\title{
Multi-Scale Microstructural Thermoelectric Materials: Transport Behavior, Non-Equilibrium Preparation, and Applications
}

\author{
Xianli Su, Ping Wei, Han Li, Wei Liu, Yonggao Yan, Peng Li, Chuqi Su, Changjun Xie, \\ Wenyu Zhao, Pengcheng Zhai, Qingjie Zhang," Xinfeng Tang," and Ctirad Uher*
}

Considering only about one third of the world's energy consumption is effectively utilized for functional uses, and the remaining is dissipated as waste heat, thermoelectric (TE) materials, which offer a direct and clean thermalto-electric conversion pathway, have generated a tremendous worldwide interest. The last two decades have witnessed a remarkable development in TE materials. This Review summarizes the efforts devoted to the study of non-equilibrium synthesis of TE materials with multi-scale structures, their transport behavior, and areas of applications. Studies that work towards the ultimate goal of developing highly efficient TE materials possessing multi-scale architectures are highlighted, encompassing the optimization of TE performance via engineering the structures with different dimensional aspects spanning from the atomic and molecular scales, to nanometer sizes, and to the mesoscale. In consideration of the practical applications of highperformance TE materials, the non-equilibrium approaches offer a fast and controllable fabrication of multi-scale microstructures, and their scale up to industrial-size manufacturing is emphasized here. Finally, the design of two integrated power generating TE systems are described-a solar thermoelectric-photovoltaic hybrid system and a vehicle waste heat harvesting systemthat represent perhaps the most important applications of thermoelectricity in the energy conversion area.

\section{Introduction}

As the worldwide reserves of fossil fuels are finite and their consumption largely contributes to carbon emission that causes serious environmental problems, developing alternative

\footnotetext{
Dr. X. Su, Dr. P. Wei, Dr. H. Li, Dr. W. Liu, Dr. Y. Yan, Prof. P. Li, Prof. C. Su, Prof. C. Xie, Prof. W. Zhao, Prof. P. Zhai, Prof. Q. Zhang, Prof. X. Tang State Key Laboratory of Advanced Technology for Materials Synthesis and Processing Wuhan University of Technology

Wuhan 430070, P.R. China

E-mail: zhangqj@whut.edu.cn; tangxf@whut.edu.cn

Dr. X. Su, Prof. C. Uher

Department of Physics

University of Michigan

Ann Arbor, MI 48109, USA

E-mail: cuher@umich.edu
}

DOI: 10.1002/adma.201602013 clean energy technologies is a major challenge for mankind. Moreover, the fact that nearly two thirds of the overall energy generated is wasted in the form of heat provides an opportunity to capture some of this waste heat and convert it into the most portable form of energy, which is electricity. This is where thermoelectricity may play an important role. ${ }^{[1-4]}$ Thermoelectric (TE) devices, because of their ability to directly convert the thermal energy into electric power and vice versa, can operate as power generators using the Seebeck effect or be utilized as coolers and refrigerators through the Peltier effect. In the former case, there is a great potential to generate electricity from solar heat and improve the fuel efficiency of cars and trucks through harvesting the exhaust heat of their engines and converting it to electricity for various auxiliary needs, including recharging batteries of hybrid vehicles. ${ }^{[5-7]}$

TE devices, which are fully solid-state with the charge carriers (electrons and holes) serving as a fuel, have the advantages of no moving parts and scalability in size and power, hence, excellent reliability, easy maintenance, and high compatibility with other functional devices and systems. One of the largest obstacles that impede large scale applications of TEs is the low conversion efficiency of TE materials. This restricts their commercialization merely to niche areas where the outstanding device reliability and scalability are at a premium and overcome limitations in the efficiency of operation. The efficiency of a TE device depends, apart from the usual Carnot efficiency, on the material's figure of merit $Z T=\sigma S^{2} T / \kappa$, where $\sigma$ is the electrical conductivity, $S$ is the Seebeck coefficient, $T$ stands for the absolute temperature measured in degrees of Kelvin, and $\kappa$ is the thermal conductivity, generally composed of the electronic part (electronic thermal conductivity, $\kappa_{e}$ ) and the lattice part (lattice thermal conductivity, $\left.\kappa_{l}\right) \cdot{ }^{[8,9]}$ High $Z T$ values over 3.0 would reach a benchmark at which the efficiency of TE-based coolers is believed to be comparable with the commercial compressorbased refrigeration. ${ }^{[10]}$ For power generation, a device with the average $Z T$ in excess of 2.0 is expected to provide an efficiency of up to $20 \%$ when subjected to a $500 \mathrm{~K}$ temperature difference 
across the hot $(800 \mathrm{~K})$ and cold sides $(300 \mathrm{~K})$ of the device. ${ }^{[1]}$ The development of materials with high $Z T$ values is thus the greatest challenge for the TE community. ${ }^{[12-17]}$

The problem is that the transport properties of semiconductors, and this includes all TE materials, are strongly interdependent and maximizing one transport parameter inevitably leads to diminishing the others. For example, enhancing the Seebeck coefficient is accompanied with lowering the electrical conductivity and vice versa. Moreover, increasing the electrical conductivity unavoidably leads to an increase in the electronic part of the thermal conductivity. ${ }^{[18,19]}$ The interdependence of the TE transport coefficients implies that the key to achieving high $Z T$ values must be a synergistic optimization of the electronic and thermal transport properties, historically a long sought goal of the materials science.

In order to promote a broad range of applications of TE technology, it is of vital importance to enhance the conversion efficiency of TE devices and systems. Specifically, thin films and nanostructured TE devices show a large improvement in the conversion efficiency. ${ }^{[20-24]}$ It has been demonstrated that superlattice-based thin film TE devices can be used as efficient coolers for highly compact microprocessors. For power generation, high-performance TE devices can be implanted into the condensed solar power generation systems or used as individual units integrated into the vehicle's exhaust system for waste heat recovery and its conversion to electricity. The above examples underline the opportunities for large scale applications of thermoelectricity that would dramatically overcome its currently limited use.

In this Review, we summarize the main progress achieved in the recent years with strategies focusing on the structure design and TE performance optimization of both materials and systems. From the perspective of materials, the multi-scale microstructure design and engineering by tailoring structural features from the atomic and molecular scales to the nanoscale and mesoscale turned out to be pivotal. The fascinating nonequilibrium synthesis approaches that enable rapid fabrication of multi-scale structures for high-performance TE materials were introduced with an eye on their potential for scaling up to industrial size production. We also describe two power generation systems, a solar TE-photovoltaic (PV) hybrid system and a vehicle waste heat recovery system, both representing the most promising TE generators (TEGs) intended for energy conversion applications. Finally, we offer an outlook concerning further developments with respect to the TE materials, devices, as well as the systems. Since this Review can cover only limited aspects of the recent progress in thermoelectricity, the readers interested in research topics covering TE property optimization, low-dimensional structures, composite and nanostructured materials, and the design and fabrication of TE modules and systems may find it useful to refer to a range of excellent review papers..$^{[5,6,12-19]}$

\section{Microstructure Dependence of Electronic and Thermal Transport in TE Materials}

From the definition of the TE figure of merit, it follows that high $Z T$ values are rooted in the material systems that exhibit

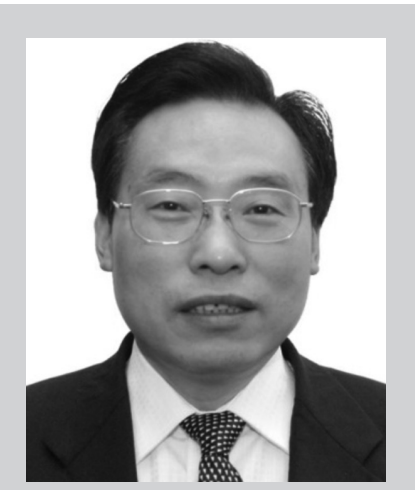

Prof. Qingjie Zhang received his Ph.D. from Huazhong University of Science and Technology in 1990. His research focuses on thermoelectric materials and related applications. At present, he is the Director of State Key Laboratory of Advanced Technology for Materials Synthesis and Processing at the Wuhan University of Technology (2005 to present) as well as the Chief Scientist of National 973 Program (2007-2017) in the field of thermoelectric materials.

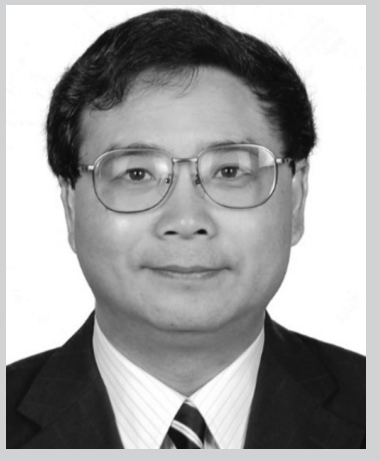

Prof. Xinfeng Tang received his Ph.D. from Tohoku University in 2000. He joined Wuhan University of Technology as a full professor in April of 2001. Now he is Deputy Executive Director for the State Key Laboratory of Advanced Technology for Materials Synthesis and Processing and Director for the Advanced Materials Research Institute, a Chair Professor of Materials Science since 2011, and a Fellow of the American Physical Society, as well as being a board member of the International Thermoelectric Society.

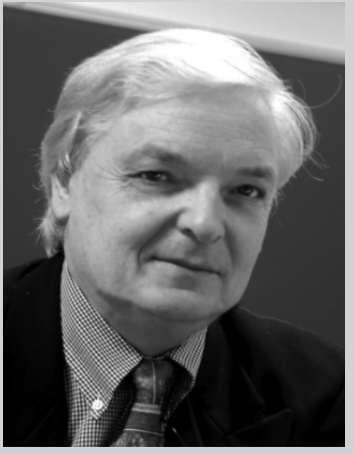

Prof. Ctirad Uher received his Ph.D. from the University of New South Wales, Australia in 1975. He was the Queen Elizabeth II Research Fellow at CSIRO, NML in Sydney and he joined the University of Michigan in 1980. At present, he is the C. Wilbur Peters Professor of Physics at the University of Michigan. Prof. Uher is a Fellow of the American Physical Society and the past President of the International Thermoelectric Society.

high electrical conductivity, large Seebeck coefficient, and low thermal conductivity. In the past decades, the traditional approach to optimize the carrier concentration and the TE performance relied on doping the host lattice with impurities. However, even under the optimized carrier concentration level, usually only moderate $Z T$ values were obtained. ${ }^{[25,26]}$ In this section, we present recent research advances regarding the optimization of the electron and phonon transport by modifying the atomic and molecular structure, and by creating nanostructures and multi-scale architectures in TE materials. 


\subsection{Optimizing Electronic and Thermal Transport at Atomic and Molecular Scales}

To make progress, it is of great importance to develop effective strategies to manipulate the electron and phonon transport. The phonon-glass electron-crystal (PGEC) concept, developed by Slack in $1995,{ }^{[7]}$ emphasized that a good TE material ought to have excellent electronic properties while its heat transport should be as inferior as that of an amorphous solid. Glass-like thermal conductivities were observed in compounds, such as filled skutterudites and clathrates, possessing open crystal structures. Filling guest atoms into the open host framework reduced the lattice thermal conductivity by introducing strong resonant phonon scattering or modifying acoustic phonon branches. ${ }^{[8,27-31]}$ Recently, based on the phase transition and thermal transport analysis of a superionic compound $\mathrm{Cu}_{2} \mathrm{Se},{ }^{[32]}$ an extremely low lattice thermal conductivity was found owing to the liquid-like phonon transport of copper ions. Moreover, the interatomic bonding played an important role and resulted in exceptionally large anharmonicity of lattice vibrations that provided a plausible explanation for the very low lattice thermal conductivity. ${ }^{[33-38]}$

There has been a flurry of interest attempting to find ways how to enhance the Seebeck coefficient while maintaining high electrical conductivity. Specifically, the effort focused on adjusting the degrees of freedom of the band structure through doping or alloying. Engineering the density-of-states (DOS) near the Fermi level proved to be the most effective way of enhancing the Seebeck coefficient. The rationality of this approach is based on the Mahan-Sofo theory ${ }^{[26]}$ and can be understood from the Mott's relation, ${ }^{[39]}$

$S=\frac{\pi^{2} k_{B}}{3 q} k_{B} T\left\{\frac{1}{n} \frac{d n(E)}{d E}+\frac{1}{\mu} \frac{d \mu(E)}{d E}\right\}_{E=E_{F}}$

where $n$ is the carrier concentration, $\mu$ is the carrier mobility, $q$ stands for the charge of an electron, $k_{B}$ is the Boltzmann constant, and $E_{F}$ is the Fermi energy. An enhanced Seebeck coefficient should arise from a rapidly varying $n$ or $\mu$ (or both) in a small energy interval close to the Fermi level. ${ }^{[40]}$ The sharply varying carrier mobility $\mu$ can be realized by introducing scattering mechanisms that have strong energy dependence. ${ }^{[41-49]}$ Rapid changes in the carrier density $n$ as a function of energy are more feasible through engineering the density of states function $g(E)$, since $n(E)=f(E) g(E)$, where $f(E)$ is the Fermi distribution function determined at $E_{F}$. Thus, a strongly energydependent DOS is crucial for the Seebeck coefficient enhancement. To manipulate the band structure, one might proceed by exploring whether it is feasible to increase the band degeneracy via band convergence ${ }^{[25,50]}$ or by introducing localized electronic resonant states. ${ }^{\left[{ }^{51,52]}\right.}$

High band degeneracy of the conduction or valence bands is potentially of great importance in TE materials since it gives rise to higher DOS effective masses and, hence, larger Seebeck coefficients with essentially no harmful effect on the carrier mobility. The enhanced band degeneracy to improve the TE performance was first reported in $p$-type $\mathrm{PbTe}^{[50]}$ as a consequence of the temperature-dependent band structure. A large band degeneracy of 12 was achieved when the band edges of the two highest lying valence bands converged at a temperature near $500 \mathrm{~K}$. Regardless of the convergence temperature being slightly higher than expected, ${ }^{[53,54]}$ the concept of band convergence has offered a new guideline for optimizing the electronic transport properties.

Band convergence can also be realized by compositionally adjusting the structure, as demonstrated recently with n-type $\mathrm{Mg}_{2} \mathrm{Si}_{1-x} \mathrm{Sn}_{x}$ solid solutions. ${ }^{[55]}$ In this case, the band convergence arises as a consequence of an inverted order of the two lowest lying conduction bands in $\mathrm{Mg}_{2} \mathrm{Si}$ and $\mathrm{Mg}_{2} \mathrm{Sn}$, shown in Figure 1. In $\mathrm{Mg}_{2} \mathrm{Si}$, the light conduction band lies lower than the heavier conduction band, while in $\mathrm{Mg}_{2} \mathrm{Sn}$, the situation is 
reversed. Thus, upon forming solid solutions of $\mathrm{Mg}_{2} \mathrm{Si}_{1-x} \mathrm{Sn}_{x}$, at some particular value of $x$, the band edges of the two conduction bands must coincide, i.e., the band convergence is realized. This happens when the concentration of $\mathrm{Sn}$ is near $x=0.7$. At this composition of the solid solution, due to an enhanced DOS effective mass, the Seebeck coefficient is maximized, which, together with the low thermal conductivity, results in exceptionally high TE performance with the $Z T=1.3$ at $700 \mathrm{~K}$. Impressive gains originating from the band convergence were subsequently reported also in $\mathrm{PbTe}, \mathrm{PbSe}, \mathrm{GeTe}, \mathrm{SnTe}$, and $\mathrm{CoSb}_{3}$ materials. ${ }^{[56-60]}$

As already stated, a sharply varying DOS near the Fermi level is a precondition for a large magnitude of the Seebeck coefficient. ${ }^{[2,61]}$ Such a scenario can be realized by introducing localized resonant states by appropriate dopants. The existence of such band resonant states has been predicted theoretically and confirmed experimentally in studies with Tl-doped PbTe. ${ }^{[51,62]}$ Enhancing the Seebeck coefficient via creating band resonant states also works well in a number of other TE materials. ${ }^{[63-67]}$

An approach based on combining multiple transport effects to synergistically optimize the TE performance was reported for In-filled $\mathrm{CoSb}_{3}{ }^{[67]}$ This material system is interesting not only because of its excellent TE performance but also because of an intense debate it generates regarding the exact crystallographic position of the In impurity. ${ }^{[68-72]}$ Recently, the technique known as X-ray absorption near edge structure (XANES) was used to probe the local atomic structure around the In atoms. It turned out ${ }^{[67]}$ that, rather than substituting on sites of $\mathrm{Sb}$ or forming a secondary phase of InSb, indium impurities prefer to occupy the central position in the Sb-icosahedron of $\mathrm{CoSb}_{3}$ when the content of In $x$ is less than 0.25 , see Figures $2 \mathrm{a}$ and 2b. Further theoretical calculations and transport measurements indicated that there is a local DOS increase near the Fermi level due to the contribution of $5 p$ electrons of In. This, presumably, is the cause of the enhanced Seebeck coefficient (Figure 2c). The orbital hybridization and charge transfer between In and $\mathrm{Sb}^{[69]}$ accelerate the electron movement and result in higher carrier mobilities (Figure 2d). Meanwhile, the In impurity located inside the oversized Sb-icosahedron gives rise to strong resonant phonon scattering. Thus, there are multiple effects associated with the exact location of the In impurity that act synergistically to optimize the performance: i) the increase in the local DOS, ii) the accelerated electron movement, and iii) resonant scattering of heat-carrying phonons.

It is also of considerable interest to be able to tune the electronic transport properties by modifying the band effective mass and the band gap. ${ }^{[73]}$ Depending on the circumstances, it is sometimes advantageous to have charge carriers with light effective masses. This is important in cases where preserving high carrier mobility, and therefore high electrical conductivity, is at a premium. ${ }^{[25]}$ The ability to tune the band gap is important to mitigate the highly undesirable bipolar diffusion because the presence of both electrons and holes not only diminishes the Seebeck coefficient but also enhances the thermal conductivity on account of the so-called ambipolar heat flow. ${ }^{[25]}$ Aided by accurate electronic structure calculations, scientists can now
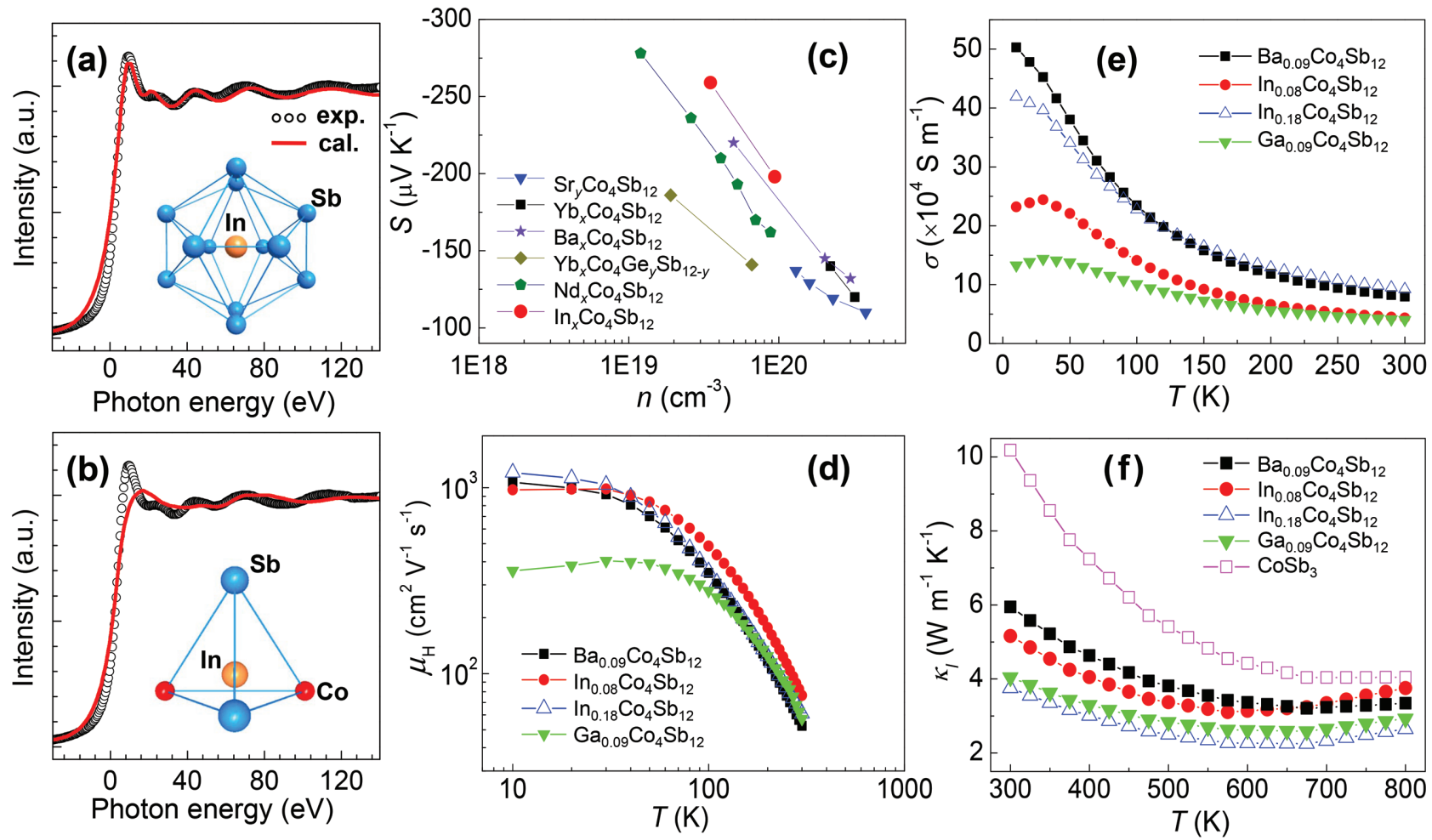

Figure 2. Simulations of the In K-edge XANES spectra of In-filled CoSb $\mathrm{C}_{3}$ when a) In impurities fill the Sb ${ }_{12}$ icosahedron voids and b) substitute for Sb sites. c) The Seebeck coefficient of n-type filled $\mathrm{CoSb}_{3}$ at room temperature as a function of carrier concentration. Temperature dependences of d) Hall

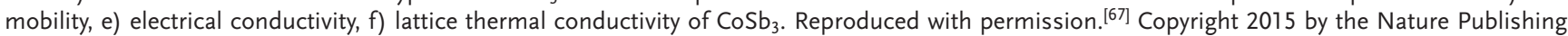
Group. 
conveniently distinguish and choose the most effective dopants among various candidates. ${ }^{[52,74]}$

\subsection{Optimizing Electronic and Thermal Transport at the Nanometer Scale}

Nanostructuring opens great opportunities for an effective alteration of the interrelated TE transport properties at the nanometer and mesoscopic scales, where the quantum confinement effect, ${ }^{[75-77]}$ energy filtering effect, ${ }^{[5,43-47]}$ and size effect $^{[78-80]}$ can have a profound influence on the TE transport properties. An optimized power factor and a reduced lattice thermal conductivity might be achieved simultaneously in nanostructured materials. These advantages have stimulated much research interest in the properties of 2D superlattice films, 1D quantum dots embedded in bulk materials, and nanocomposite structures, where high $Z T$ values have been reported. [78-83]

Benefiting from the low cost and high scalability, the fabrication of nanostructured bulk materials has become one of the most important strategies to develop high-performance TE materials. ${ }^{[84-89]}$ However, one should always keep in mind that the presence of nanoinclusions might adversely affect the conducting carriers. It is therefore imperative to engineer the nanostructures so that they preferentially scatter heat-carrying phonons and leave the charge carrier transport substantially intact. From the band structure point of view, nanoinclusions or nanoscale imperfections should have only a small band edge offset with respect to the band edge of the matrix. ${ }^{[53]}$ For example, in an n-type nanocomposite, the nanoinclusions and the matrix should have their respective conduction band edges closely matched with the energy difference of no more than a few $k_{\mathrm{B}} T$ to ensure minimal electron scattering at the interface barriers. This concept of minimum band offset has been experimentally adopted in several studies, including those on p-type SrTe-doped PbTe and CdS-doped PbS materials. ${ }^{[90,91]}$

The morphology of interfaces and boundaries in nanostructured materials is also important. Several experimental and theoretical studies have demonstrated that the carrier mobility can be retained when the interface is atomically coherent or aligned to within very small angles. ${ }^{\left[{ }^{[2-97]}\right.}$ As an example, a small angle neutron scattering (SANS) technique was employed to determine the nature of nanoscale interfaces of embedded nanocrystals in the $(\mathrm{Bi}, \mathrm{Sb})_{2} \mathrm{Te}_{3}$ nanocomposite structure (Figure 3). The power law exponent close to 4 , derived from the plot of phonon intensity as a function of the neutron momentum transfer, confirmed that interfaces between the nanoinclusions and the bulk matrix are mostly coherent. Such coherent boundaries, together with the nanoscale modulation and a small volume of the amorphous phase, resulted in a dramatic reduction in the lattice thermal conductivity. ${ }^{[95]}$ Compared to commercial ingots, the nanocomposite structures exhibited significantly improved $Z T$ values.

\subsection{Optimizing Electronic and Thermal Transport Properties Via Multi-Scale Microstructures}

Developing multi-scale TE materials containing different dimensional features spanning from the atomic and molecular scales to the nanoscale and the mesoscale can be more effective compared to the regular nanostructuring approach. ${ }^{[53,98]}$ In a material with multi-scale structural features, a broad
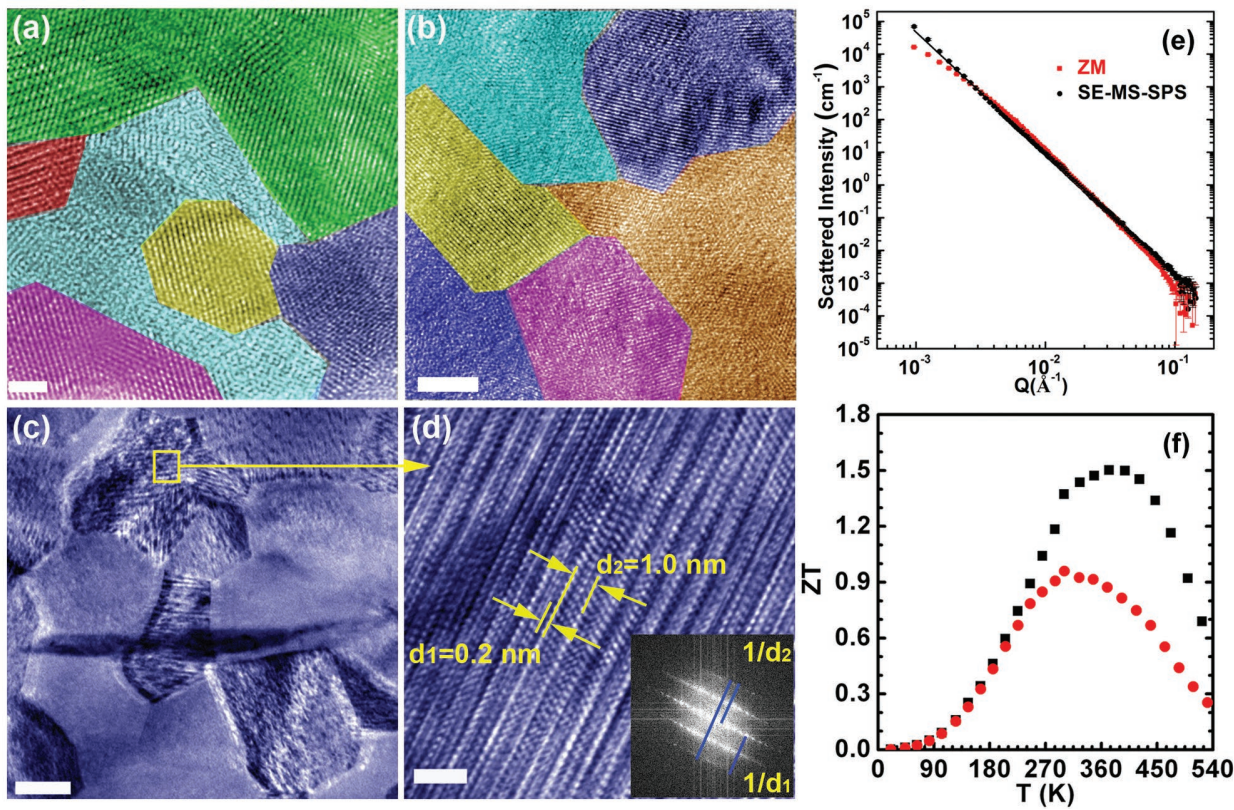

Figure 3. TEM images of $(\mathrm{Bi}, \mathrm{Sb})_{2} \mathrm{Te}_{3}$ nanostructured bulk materials: a) and b) HRTEM images of typical microstructures containing 10-20 nm nanocrystals embedded in the bulk matrix; c) and d) HRTEM images of nanoscale modulations. e) SANS intensities as a function of momentum transfer $\mathrm{Q}$ in a double-logarithmic plot. ( $\mathrm{f}$ ) Values of the TE figure of merit $Z T$ of the commercial ingots and nanocomposite materials. The scale bars for a, b, c, and d are 2, 5, 100, and $2 \mathrm{~nm}$, respectively. Reproduced with permission. ${ }^{[95]}$ Copyright 2010 by the American Chemical Society. 
spectrum of phonons from high to low frequencies can be selectively scattered on the atomic and molecular scales by point defects, dislocations, and resonant rattlers; or be affected on the nanometer scale by boundaries, nanoinclusions, nanoprecipitates, and nanopores; and, finally, on the mesoscale by fine grains and micropores, leading to a lower lattice thermal conductivity. In contrast, electrons experience considerably fewer scattering events because of the existence of coherent interfaces or endotaxially embedded nanoprecipitates, and also due to the influence of the percolation effect, which means that the electrons prefer to flow in the channels connected by the mesoscale grains, as demonstrated in some nano/micro composite structures. ${ }^{[86,99-101]}$

As a consequence of the much stronger phonon scattering and less intense electron scattering in multi-scale structures, a large ZT of about 2.2 was realized in p-type $\mathrm{PbTe}$ containing an endotaxially embedded SrTe nanophase. ${ }^{[98]}$ The advantages of multi-scale structures were documented in several studies, including the reproducibility and resilience of the nanophase, ${ }^{[53]}$ and it is gratifying that the strategy works well even with commercial TE materials.

Two different synthesis techniques have been employed to fabricate multi-scale $\mathrm{Bi}_{2} \mathrm{Te}_{3}$-based materials, and both have led to a significantly improved TE performance. ${ }^{[102,103]}$ One study was carried out with commercial n-type zone-melted (ZM) ingots using a direct hot deformation treatment. The multiscale features, including the microscale grain size reduction and texture loss, nanoscale distorted regions, and atomic scale lattice distortions and point defects, were clearly resolved with the aid of advanced electron microscopy techniques. A high $Z T$ of 1.2 at $357 \mathrm{~K}$ was reported in the n-type $\mathrm{Bi}_{2} \mathrm{Te}_{3}$-based material. ${ }^{[03]}$ In the other work, melt spinning was followed by spark plasma sintering (MS-SPS) to treat the commercial p-type ZM ingots. As shown in Figure 4, the achieved multi-scale structure consists of dislocations, sub-microscale to nanoscale grains, twin boundaries, and nanoprecipitates, which all contribute to scattering of phonons over a broad range of frequencies. A peak $Z T$ of 1.22 was yielded at $340 \mathrm{~K}$ due to a significant reduction in the lattice thermal conductivity (Figure 4f). It should also be noted that the MS-SPS materials show robust mechanical properties and excellent thermal stability, implying a great prospect for large scale applications of such $\mathrm{Bi}_{2} \mathrm{Te}_{3}$-based materials.

There is no doubt that multi-scale structural architectures greatly aid in achieving high TE performance. This direction of research has inspired a flurry of interest in exploring effective approaches to fabricate such multi-scale TE materials using fast, inexpensive, scalable, and controllable synthesis processes. In the following paragraphs, we focus on non-equilibrium synthesis techniques to fabricate multi-scale TE materials. Specifically, we describe the technique of melt spinning and the selfpropagating high-temperature synthesis.

\section{Non-Equilibrium Preparation of Multi-Scale Microstructural TE Materials}

The preparation of multi-scale TE materials strongly depends on the synthesis approaches employed and specific conditions of the synthesis process. So far, bulk TE materials have been synthesized mostly by one of the following methods: melting followed by slow cooling, ${ }^{[104-107]}$ melting combined with longtime annealing, ${ }^{[108-113]}$ multi-step solid-state reactions, ${ }^{[114,115]}$ and mechanical alloying. ${ }^{[63]}$ According to the phase reaction and formation thermodynamics, the synthesis approaches used to
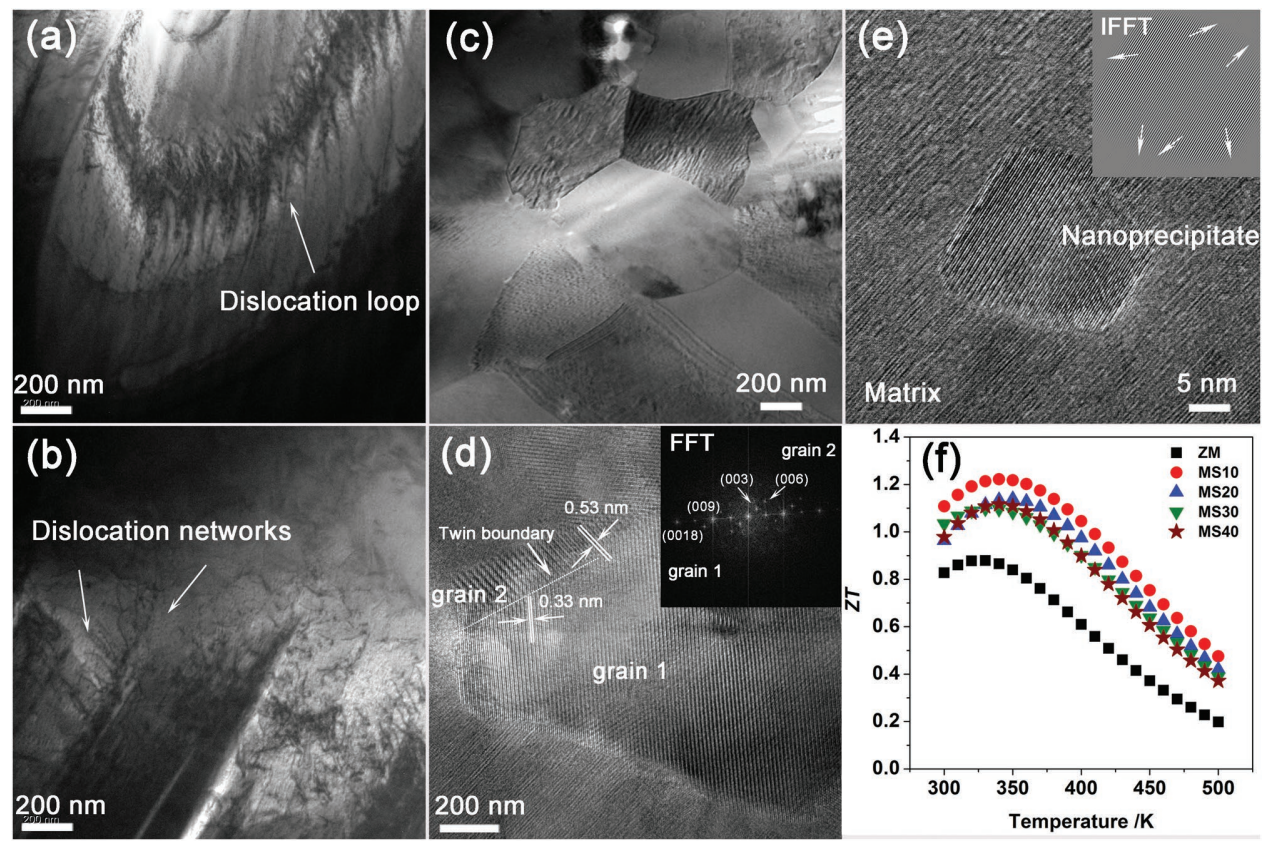

Figure 4. HRTEM images of a) ZM ingots with large dislocation loops, b) intricate dislocation networks on the cleavage plane, c) the MS10 sample with d) twin boundaries, and e) nanodots. The insets in (d) and (e) show the FFT and IFFT images of the corresponding twin crystals and the nanodot, respectively. $f$ ) Temperature dependence of $Z T$ values for the ZM ingot, MS-SPS specimens, and MS10 annealed sample denoted by MS10-A. Reproduced with permission. ${ }^{[102]}$ Copyright 2015 by Wiley-VCH. 
fabricate bulk TE materials can be classified into equilibrium processes and non-equilibrium processes. For example, zone melting, melting followed by slow cooling, melting combined with long-time annealing, and multi-step solid state reactions can be classified as equilibrium processes. In contrast, mechanical alloying, hot deformation, ${ }^{[116]}$ melt spinning (MS) ${ }^{[117-142]}$ and the self-propagating high-temperature synthesis (SHS) ${ }^{[102,143-148]}$ are typical examples of non-equilibrium processes. In this section, we emphasize two non-equilibrium synthesis approaches: melt spinning and SHS. Both synthesis techniques are very fast, scalable, and controllable, as required for a large scale fabrication of high-performance multi-scale TE materials.

\subsection{Melt Spinning}

The melt spinning (MS) technique has been widely utilized to produce amorphous alloys. The melt spinning process is schematically shown in Figure 5a. During the spinning process, the viscoelastic molten fluid is ejected from a capillary tube onto a high-speed rotating cold copper roller to form thin ribbons at ultrahigh cooling rates of $10^{5}-10^{7} \mathrm{~K} \mathrm{~s}^{-1}$. The morphology of the contact surface and the free surface of the ribbons can be substantially different due to the different cooling rates at the two surfaces. This is manifested by different microstructures forming under much higher cooling rates at the contact surface than under more modest cooling rates at the free surface of the ribbons.

The inhomogeneous cooling process is the most essential aspect in synthesizing high performance TE materials with multi-scale architectures. ${ }^{[102]}$ Taking the commercial $\mathrm{Bi}_{2} \mathrm{Te}_{3}$ based material as an example, a hierarchical microstructure of $(\mathrm{Bi}, \mathrm{Sb})_{2} \mathrm{Te}_{3}$ ribbons varies continuously from the contact surface to the free surface, as depicted in Figure 5b-f. Close to the contact surface, amorphous phases are found since the surface is subjected to the highest cooling rate. Off the contact surface and inside the ribbons, where the cooling rate is gradually lower, numerous 5-10 $\mathrm{nm}$ fine nanoparticles are observed. Close to the free surface, a large number of microscale dendritic crystals are present. Thus, a wide range of multi-scale structures, all with the same composition as determined by
EDS on the micro-scale, constitutes the thickness of the meltspun ribbons.

To carry out transport property measurements and, eventually, to assemble TE modules, densification of the structure to a near theoretical density is necessary. Spark plasma sintering (SPS), sometimes also called plasma assisted sintering (PAS), (PAS), has proved to be very useful and convenient to densify powders of multi-scale structures. The essential point is that the multi-scale structures are exposed to high temperatures for only a very short time of a few minutes, unlike in the traditional high temperature press where densification can take hours. Consequently, their multi-scale structure is substantially preserved during the sintering process. Such rapid sintering is achieved with the aid of high current pulses applied as the powder is being compressed. Figure 4 shows the microstructure of $(\mathrm{Bi}, \mathrm{Sb})_{2} \mathrm{Te}_{3}$ bulk samples obtained by MS-SPS. ${ }^{[102]}$ The hierarchical structure of particles ranging from several nanometers to 20 micrometers is readily observed.

Due to enhanced phonon scattering from the multi-scale structure, ${ }^{[118]}$ the lattice thermal conductivity between 300 and $400 \mathrm{~K}$ has been reduced from $0.8-0.9 \mathrm{Wm}^{-1} \mathrm{~K}^{-1}$ for the zone melted ingots down to $0.4-0.5 \mathrm{Wm}^{-1} \mathrm{~K}^{-1}$ for the MS-SPS samples. In addition, the multi-scale structures tend to effectively suppress the bipolar thermal conductivity because of selective scattering of the minority carriers at the interface barriers. All these effects contribute to an increase of $50 \%$ or more in the highest ZT compared to samples originating from zone melted ingots. ${ }^{[95]}$

The preparation of samples with multi-scale structure by melt spinning, as demonstrated in the case of commercial $\mathrm{Bi}_{2} \mathrm{Te}_{3}$ based materials, is also applicable to other important TE materials, including $\mathrm{CoSb}_{3},{ }^{[122-131]}$ clathrates, ${ }^{[132,141]} \mathrm{MnSi}_{1.75-x},{ }^{[135]}$ and $\mathrm{AgSbTe}_{2} \cdot{ }^{[136]}$ Skutterudite samples with the composition $\mathrm{CoSb}_{2.75} \mathrm{Ge}_{0.05} \mathrm{Te}_{0.20}$ synthesized by MS-SPS ${ }^{[125]}$ possessed numerous nanograins on the scale of several hundred nanometers and a large number of nanodots with the average diameter of 15-20 nm embedded in the skutterudite matrix. Benefiting from the multi-scale structure, the phonon mean free path at $2.6 \mathrm{~K}$ was reduced from $9 \mu \mathrm{m}$ in $\mathrm{CoSb}_{2.75} \mathrm{Ge}_{0.05} \mathrm{Te}_{0.20}$ synthesized by the traditional method to $1.4 \mu \mathrm{m}$ in the MS-SPS sample. At ambient temperatures, the two respective values became $2.2 \mathrm{~nm}$ and $1.3 \mathrm{~nm}$. The decrease of the phonon mean free path in $\mathrm{CoSb}_{2.75} \mathrm{Ge}_{0.05} \mathrm{Te}_{0.20}$ was attributed to the grain refinement and nanoscale precipitates in the matrix. ${ }^{[125]}$

In Table 1 are summarized $Z T$ values of various TE materials prepared by MS-SPS. The figure of merit ZT of these MS-SPSprepared samples is comparable to or even higher than for samples synthesized by other methods. Moreover, and this is especially the case of skutterudites, in contrast with the traditional synthesis methods, the MS-SPS process dramatically shortens the synthesis time from more than one week to less than 20 hours. $^{[129,130]}$ Thus, melt spinning combined with rapid sintering, such as achieved via SPS, represents a fast, controllable, and scalable technique of fabricating multi-scale structures with improved TE performance.
Figure 5. a) Diagram of the melt spinning process indicating the free surface (FS) and the contact surface (CS) of the resulting melt-spun ribbon. b) Cross section images of the ribbon. c-e) TEM images of different areas inside the ribbon. $f$ ) Free surface TEM image of the ribbon. Reproduced with permission. ${ }^{[18]}$ Copyright 2009 by the American Institute of Physics. 
Table 1. Thermoelectric properties of samples synthesized by melt spinning combined with SPS.

\begin{tabular}{lccc}
\hline Materials & Carrier type & $Z T_{\max }$ & Refs. \\
\hline $\mathrm{Bi}_{0.52} \mathrm{Sb}_{1.48} \mathrm{Te}_{3}$ & $\mathrm{p}$ & $1.56(300 \mathrm{~K})$ & {$[118]$} \\
$\mathrm{Bi}_{0.48} \mathrm{Sb}_{1.52} \mathrm{Te}_{3}$ & $\mathrm{p}$ & $1.5(300 \mathrm{~K})$ & {$[95]$} \\
$\left(\mathrm{Bi}_{0.85} \mathrm{Sb}_{0.15}\right)_{2}\left(\mathrm{Te}_{0.83} \mathrm{Se}_{0.17}\right)_{3}$ & $\mathrm{n}$ & $0.96(360 \mathrm{~K})$ & {$[140]$} \\
$\left(\mathrm{Bi}_{0.95} \mathrm{Sb}_{0.05}\right)_{2}\left(\mathrm{Te}_{0.85} \mathrm{Se}_{0.15}\right)_{3}$ & $\mathrm{n}$ & $1.0(460 \mathrm{~K})$ & {$[139]$} \\
$\mathrm{Yb}_{0.2} \mathrm{Co}_{4} \mathrm{Sb}_{12.3}$ & $\mathrm{n}$ & $1.26(800 \mathrm{~K})$ & {$[130]$} \\
$\mathrm{Yb}_{0.3} \mathrm{Co}_{4} \mathrm{Sb}_{12.3}$ & $\mathrm{n}$ & $1.3(800 \mathrm{~K})$ & {$[129]$} \\
$\mathrm{Yb}_{0.3} \mathrm{Co}_{4} \mathrm{Sb}_{12}$ & $\mathrm{n}$ & $1.22(800 \mathrm{~K})$ & {$[128]$} \\
$\mathrm{Nd}_{0.6} \mathrm{Yb}_{0.4} \mathrm{Fe}_{3} \mathrm{CoSb}_{12}$ & $\mathrm{p}$ & $0.55(750 \mathrm{~K})$ & {$[126]$} \\
$\mathrm{CeFe}_{4} \mathrm{Sb}_{12}$ & $\mathrm{p}$ & $1.0(800 \mathrm{~K})$ & {$[122]$} \\
$\mathrm{MnSi}_{1.75-x}$ & $\mathrm{p}$ & $0.62(800 \mathrm{~K})$ & {$[135]$} \\
$\mathrm{InSb}$ & $\mathrm{n}$ & $0.49(700 \mathrm{~K})$ & {$[133]$} \\
$\mathrm{AgSbTe}_{2}$ & $\mathrm{p}$ & $1.65(570 \mathrm{~K})$ & {$[136]$} \\
$\mathrm{Zn}_{4} \mathrm{Sb}_{3}$ & $\mathrm{p}$ & $1.16(700 \mathrm{~K})$ & {$[137]$} \\
$\left(\mathrm{Zn}_{0.99} \mathrm{Cd}_{0.01}\right)_{4} \mathrm{Sb}_{3}$ & $\mathrm{p}$ & $1.3(700 \mathrm{~K})$ & {$[138]$} \\
$\mathrm{Ba}_{8} \mathrm{Ga}_{12} \mathrm{Zn}_{2} \mathrm{Ce}_{12}$ & $\mathrm{n}$ & $0.9(900 \mathrm{~K})$ & {$[141]$} \\
$\mathrm{Mg}_{2}\left(\mathrm{Si}_{0.3} \mathrm{Sn}_{0.7}\right)_{0.98} \mathrm{Sb}_{0.02}$ & $\mathrm{n}$ & $1.3(750 \mathrm{~K})$ & {$[117]$} \\
\hline
\end{tabular}

\subsection{Self-Propagating High-Temperature Synthesis}

SHS represents another non-equilibrium synthesis technique with the advantages of rapid processing, good scalability, and energy savings. SHS has been used to prepare refractory materials, ${ }^{[149]}$ high purity ceramics, ${ }^{[150]}$ and intermetallics. ${ }^{[151]}$ Its essential feature is a spontaneously propagating combustion wave driven by a highly exothermic nature of chemical reactions taking place in a loosely compacted powder of elemental species. The synthesis is initiated by point heating a small part of the sample. Once the ignition starts, the combustion wave passes through the remaining sample as the liberated heat of fusion in one section is sufficient to maintain the reaction in the neighboring region. The propagation of the combustion wave is fast, typically on the timescale of seconds, and the final product is usually of high purity because of the endowed feature of self-purification.

Combining SHS with subsequent PAS processing, several excellent bulk TE materials, including $\mathrm{Cu}_{2} \mathrm{Se}, \mathrm{Bi}_{2} \mathrm{Te}_{3}$-based alloys, skutterudites, SnTe, $\mathrm{ZrNiSn}, \mathrm{Cu}_{2} \mathrm{SnSe}_{3}$, and $\mathrm{Mg}_{2} \mathrm{Si}_{1-x} \mathrm{Sn}_{x}$ were prepared. ${ }^{143-148]}$ Taking $\mathrm{Cu}_{2} \mathrm{Se}$ as an example, and as discerned from the infrared images shown in Figure 6a, the SHS process in $\mathrm{Cu}_{2} \mathrm{Se}$ can be classified into three main stages: i) local ignition, ii) combustion wave passing through, and iii) product cooling. The initial heating rate must be reasonably high, more than $200 \mathrm{~K} \mathrm{~s}^{-1}$ in the case of $\mathrm{Cu}_{2} \mathrm{Se}$. The combustion temperature at the center of the pellet reached $835 \mathrm{~K}$ and thereafter decreased rapidly (Figure 6b). The speed of the propagating combustion wave was $5.6 \mathrm{~mm} \mathrm{~s}^{-1}$, a rather low value but within the range of speeds of $1-250 \mathrm{~mm} \mathrm{~s}^{-1}$ reported for other materials. ${ }^{[152-154]}$

Using this ultrafast SHS method, reactive and metastable products can be obtained with high defect concentrations and non-equilibrium structures, which are favorable for the formation of multi-scale architectures in the final product. Corn-like nanostructured $\mathrm{Cu}_{2} \mathrm{Se}$ with homogeneous composition was formed directly following the passing by of the combustion wave in a time span of a few seconds, as shown in Figure 7. A large range of nanoinclusions is maintained after the SPS treatment, with sizes in the range from 10 to $30 \mathrm{~nm}$, evenly distributed on grain faces of the matrix, as shown in Figure 7. Furthermore, the interface between the nanoinclusions and the matrix remains substantially coherent. Thus, while phonons are strongly scattered, the carrier transport is only little impeded.

Both the electrical conductivity and the Seebeck coefficient of $\mathrm{Cu}_{2}$ Se synthesized by SHS-SPS is higher than that of a sample designated as M-AN-SPS, prepared by traditional melting and long-term annealing followed by SPS. Due to the enhanced power factor and the lower thermal conductivity, the maximum $Z T$ value as high as 1.8 was achieved at $1000 \mathrm{~K}$ for this SHSSPS sample. Meanwhile, the SHS-SPS sample showed good thermal stability. Its TE properties were essentially unchanged after the annealing treatment of 3 weeks at $800 \mathrm{~K}$ under vacuum. ${ }^{[143]}$ Table 2 summarizes TE properties of various materials prepared by SHS-SPS. The figure of merit $Z T$ of samples prepared by SHS-SPS is comparable to or even better than samples synthesized by other methods. Due to the ultrafast and non-equilibrium nature of the process, SHS opens a new avenue for rapid, low cost, and large scale mass production of nanostructured TE materials.

\section{Thermoelectric Applications}

\subsection{Solar TE-PV Hybrid Power Generation Technology}

Full spectrum high efficiency solar power generation is a renewable clean energy conversion technology that has attracted worldwide attention. The PV system based on silicon cells is (a)

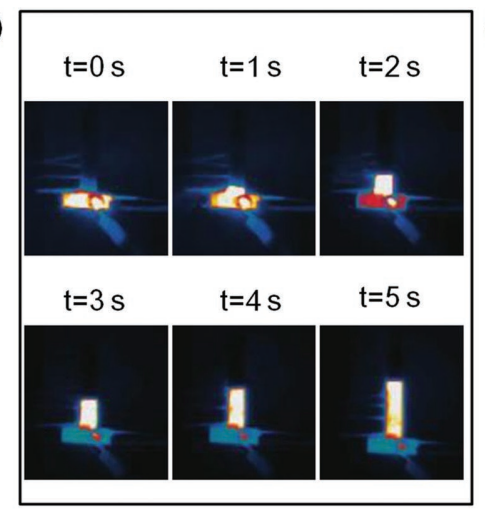

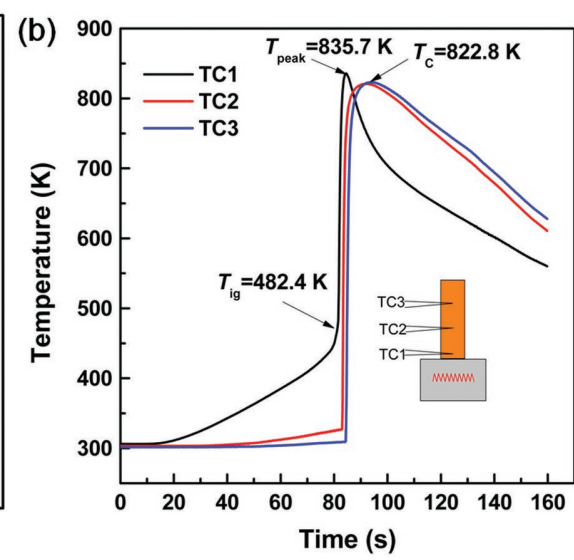

Figure 6. Characteristics of the SHS synthesis. a) Infrared photos of different stages of the SHS process. b) Temperature profile of the thermocouples at different positions along the length of the ingot. Reproduced with permission. ${ }^{[143]}$ Copyright 2014, Nature Publishing Group. 

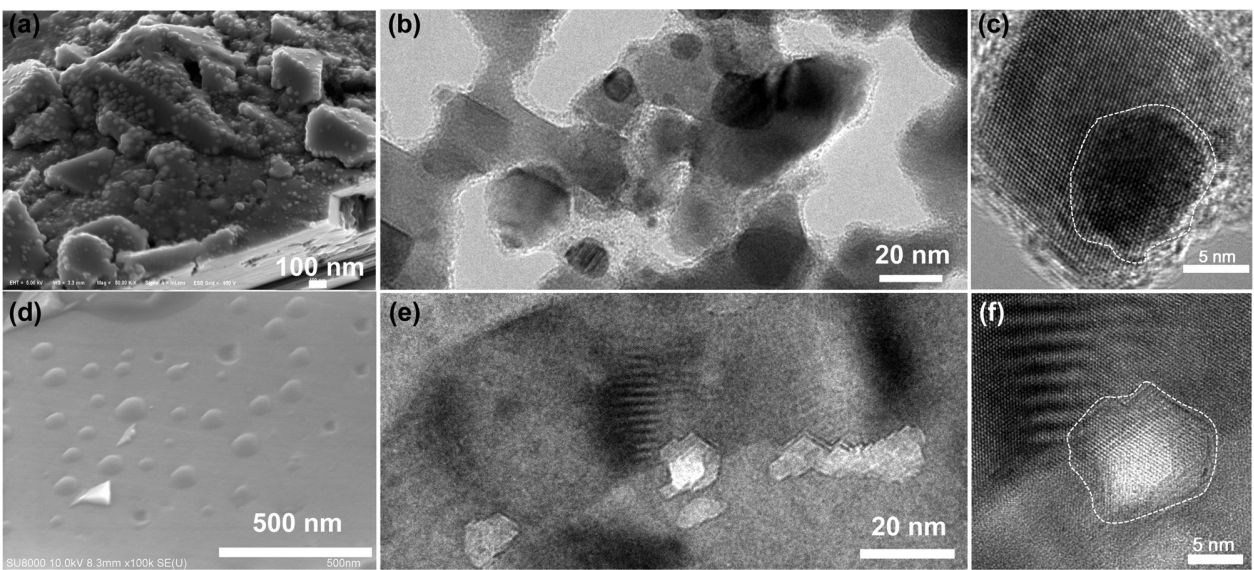

Figure 7. Microstructures of $\mathrm{Cu}_{2} \mathrm{Se}$ nanostructured materials prepared by SHS-SPS. a) FESEM image of the SHS product; $\left.b, c\right)$ HRTEM photos of the SHS product; d) FESEM image of the SHS-SPS bulk; e,f) HRTEM photos of the SHS-SPS bulk. Reproduced with permission. ${ }^{[143]}$ Copyright 2014 by the Nature Publishing Group.

the dominant commercial selection and provides about $15 \%$ energy conversion efficiency because the silicon cells respond efficiently to only the ultraviolet and visible range of the solar spectrum. The concentrating photovoltaic (CPV) system based on multi-junction solar cells can utilize the ultraviolet and visible light, and part of the infrared light, which improves the overall efficiency of solar energy conversion to $25 \%$, and largely reduces the costs of semiconductor materials relative to the PV system. However, the CPV system produces huge infrared thermal load in the cells due to a high concentration ratio, which consequently leads to the system's reduced conversion efficiency and poor reliability. The problem becomes a significant constraint on large scale applications of high concentrating photovoltaic (H-CPV) systems.

In 2003, Zhang and Niino co-proposed the scientific concept of solar TE-PV hybrid power generation (Figure 8). ${ }^{[155]}$ They separate the full spectrum sunlight ranging from 200 to $3000 \mathrm{~nm}$ in wavelength, as shown in the top right corner of Figure 8, through a sunlight splitter into ultraviolet and visible light, and infrared light. Then, the system utilizes solar cells to convert the separated ultraviolet and visible light, which is about $58 \%$ of the solar radiation energy, and TE devices to convert the separated infrared light, which is about $42 \%$ of the solar radiation energy. The sub-PV system and the sub-TE system are finally integrated to form a hybrid power generation system. The hybrid system can significantly reduce the huge thermal

Table 2. Thermoelectric properties of samples synthesized by SHS combined with SPS.

\begin{tabular}{lccc}
\hline Materials & Carrier type & $Z T_{\max }$ & Refs. \\
\hline $\mathrm{Cu}_{2} \mathrm{Se}$ & $\mathrm{p}$ & $1.80(1000 \mathrm{~K})$ & {$[143]$} \\
$\mathrm{Cu}_{2} \mathrm{Sn}_{1-x} \mathrm{In}_{x} \mathrm{Se}_{3}$ & $\mathrm{p}$ & $1.42(875 \mathrm{~K})$ & {$[143]$} \\
$\mathrm{Bi}_{2} \mathrm{Te}_{3-x} \mathrm{Se}_{x}$ & $\mathrm{n}$ & $0.95(423 \mathrm{~K})$ & {$[144]$} \\
$\mathrm{Mg}_{2} \mathrm{Si}_{1-x} \mathrm{Sb}_{x}$ & $\mathrm{n}$ & $0.65(873 \mathrm{~K})$ & {$[148]$} \\
$\mathrm{CoSb}_{3-x} \mathrm{Te}_{x}$ & $\mathrm{n}$ & $0.98(820 \mathrm{~K})$ & {$[145]$} \\
$\mathrm{MnSi}_{1.75-x} \mathrm{Ge}_{x}$ & $\mathrm{p}$ & $0.62(840 \mathrm{~K})$ & {$[147]$} \\
$\mathrm{ZrNiSn}$ & $\mathrm{n}$ & $0.67(800 \mathrm{~K})$ & {$[143]$} \\
\hline
\end{tabular}

load in the PV cells due to the separate utilization of the solar spectrum and thereby achieve high efficiency full spectrum solar power generation.

Under the joint support from the NSF and MOST of China, and JST of Japan, research on solar TE-PV hybrid power generation technology has witnessed much progress since 2003. A theoretical model has been proposed to quantitatively describe the relationship between the overall efficiency of the solar TE-PV hybrid system and various parameters of the PV and TE subsystems. ${ }^{[15]}$ A design method has been established to optimize the hybrid system parameters. A series of integration technologies have been developed, such as the PV cell/TE device/splitter integration into a hybrid unit, the hybrid unit/ Fresnel lens integration into a module, and the module/sun tracking system integration into the hybrid system. ${ }^{[156]}$ Meanwhile, the simply structured and scale-manufactured hybrid unit and module were developed (Figure 9). Four distributed hybrid systems with an output power of $1-5 \mathrm{~kW}$ were successfully built. Specifically, two of them have been operating for 10 years in Sendai, Japan, and the other two have been running

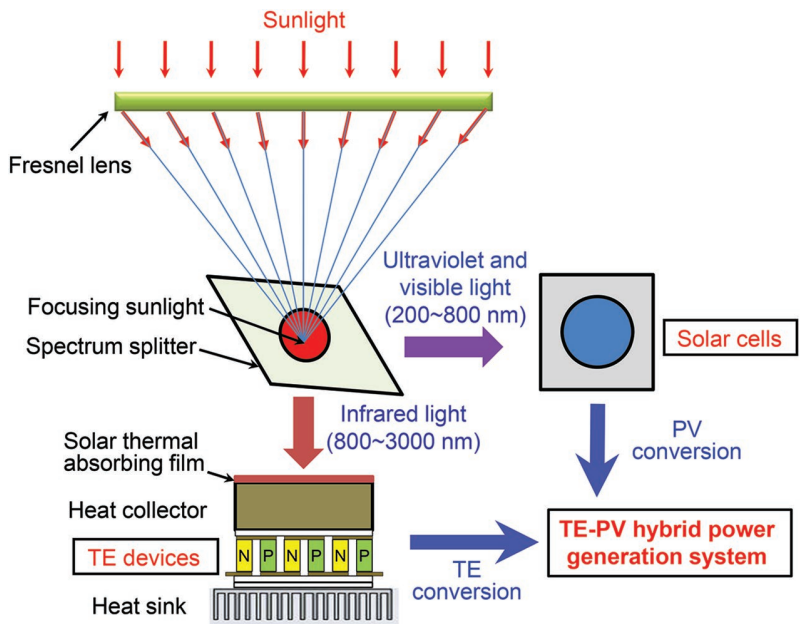

Figure 8. Scheme for solar TE-PV hybrid power generation system. 


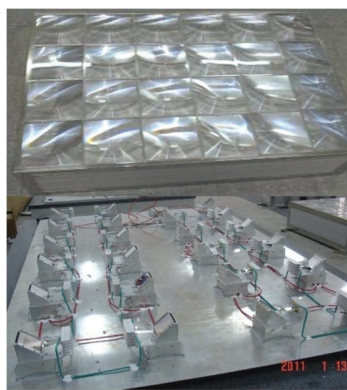

Hybrid Module

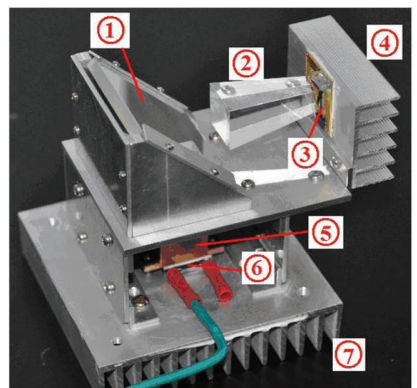

Hybrid Unit
(1) Spectrum splitter

(2) Energy homogenizer (3) PV cell

(4) Heat sink for PV cell (5) Heat collector (6) TE device (7) Main heat sink

Figure 9. Configuration of TE-PV hybrid power generation unit and module.

for 5 and 9 years in Wuhan, China. One large grid-connected hybrid system with an output power of $100 \mathrm{~kW}$ and a concentration ratio of 1050 was also built in Xining, China. The efficiency of the large system is up to $30 \%$. The maximum operating temperature of the TE devices in the system was measured up to $500{ }^{\circ} \mathrm{C}$ and that of the PV cells below $70^{\circ} \mathrm{C}$, even though cooled with only a simple and cheap heat radiation system. The TE-PV hybrid power generation system overcomes the constraint regarding widescale applications of $\mathrm{H}-\mathrm{CPV}$ technology, and provides a new strategy for the development of full spectrum and high efficiency solar power generation technology.

\subsection{Automobile Exhaust TE Power Generation Recycling Technology}

Automobiles lose $40 \%$ of their fuel energy to the environment through the exhaust pipe. In 2014, the number of Chinese civilian automobiles amounted to 146 million, and the total exhaust waste heat was equivalent to 120 million tons of fuel, representing about $25 \%$ of Chinese annual fuel consumption. The recovery and utilization of automobile exhaust waste heat could play a vital role in energy savings and emissions reductions in both China and the rest of the world. However, the recovery and conversion of the waste heat is a challenging problem, mainly due to the low level of heat typified by temperatures ranging from 200 to $600{ }^{\circ} \mathrm{C}$, low density, and the distributed nature of the waste heat. Meanwhile, the recycling of the waste heat becomes extremely difficult in a moving environment, thus other energy saving and emission reduction technologies such as heat pipes have not achieved high efficiency recycling. With the development and breakthroughs in the TE technology in the recent ten years, TEGs have been recognized as a promising new technology to effectively recover the waste heat, providing a great opportunity to solve the huge energy waste problem. In 2009, the MOST and NEA of China, and the US Department of Energy co-signed the China-US Strategic Cooperation Agreement on Clean Energy, emphasizing the automobile exhaust heat recovery and its conversion to electricity via TE power generation as a major supported research activity of the China-US cooperation.

With the joint support by the Chinese 973 Program and Key Projects of China-US International Cooperation, the Chinese research team composed of scientists from the Wuhan University of Technology and the Dongfeng Motor Corporation has made significant progress on the key technologies of automobile exhaust TE power generation recycling and on the development of a TEG demonstration automobile with the cooperation of the University of Michigan. Various kinds of highly efficient TE devices have been manufactured, such as the $\mathrm{CoSb}_{3}$ based on-vehicle TE power generator operating in the temperature range of $250-550^{\circ} \mathrm{C}$ with an efficiency of $8.1 \%$, the $\mathrm{CoSb}_{3} / \mathrm{Bi}_{2} \mathrm{Te}_{3}$ based on-vehicle installed TEG operating to temperatures up to $\approx 550{ }^{\circ} \mathrm{C}$ with an efficiency of $10.1 \%$ and output power density of $1.1 \mathrm{~W} / \mathrm{cm}^{2}$, and the Mg-Si-Sn-based TE power generator with an efficiency of $8.1 \%$. These TE devices show good on-vehicle environmental adaptability. Two types of highly integrated and easily scale-manufactured TEG/exhaust pipe integrated structures have been developed. Both of them can channel $30-50 \%$ of the waste heat to TEG with no impediment to the operation of the engine. ${ }^{[157,158]}$ A new $48 \mathrm{~V}$ automobile power source energy management strategy has been proposed to maximize the power output of TEG systems and provide effective utilization of the electric energy generated by the TEG system. ${ }^{[159,160]}$ With the Dongfeng warrior vehicle, a weak hybrid drive scheme using the TEG system was able to recycle $940 \mathrm{~W}$ of the electric energy in the drum bench and reduced by $15 \%$ the fuel cost. In the road driving test, the TEG generated 620 W. With the Dongfeng Tianlong DFL4181A8 heavy truck, the TEG/SCR catalyst/muffler integrated TEG system helped to recover $1.5 \mathrm{~kW}$ of electric energy from the exhaust heat, which was used to operate the local intelligent air conditioning system in the cabin and other on-vehicle electrical appliances, reducing in the process the fuel consumption by $2-3 \%$.

\subsection{TEG Application in New Type Environment Friendly River-Sea Ships}

The Yangtze River is the No. 1 vital inland waterway globally with the top freight volume as well as the most important eastto-west waterway artery in China. The development of new energy saving and environment friendly river-sea ships with TEG technology has been included in the National Key Research and Development Program. According to the program, 10000 such ships should be built by the year 2030. The Chinese TE research team led by the Wuhan University of Technology has designed a TEG system with an output power of $20 \mathrm{~kW}$ that can be applied to the new energy saving and environment friendly river-sea vessels. The recovered electric energy is used to power various electrical appliances on the ships. This ten thousand tons energy saving and environment friendly multipurpose new river-sea ship (980TEU) has been reviewed by the China Classification Society, and will be completed and put into use by the end of 2018 .

\section{Conclusions and Outlook}

Understanding the transport behavior of electrons and phonons as they pass through diverse lattice structures is the key to 
regulating the TE properties and exploring novel advanced TE materials. The use of non-equilibrium preparation methods, such as melt-spinning and combustion synthesis, offers a quick and efficient way to achieve multi-scale microstructures that are advantageous in rationally tuning the electron and phonon transport processes and therefore the dimensionless TE figure of merit $Z T$, which governs the TE conversion efficiency. However, a further decoupling of electrical and thermal transport properties and higher TE performance are needed for the large scale economically viable applications of TE materials. It is of considerable interest to explore TE properties in systems with unique forms of electron transport governed by distinct energy dependencies, such as heavy fermions, magnetic nanoparticles, and surface states of topological insulators. Designing and engineering nanoscale heterogeneous interfaces is also of great importance in order to pursue energy filtering effects that dramatically enhance the Seebeck coefficient. Implementation of the above strategies will be highly beneficial for the development of a new generation of efficient TE materials that will impact both the power generation as well as cooling technologies.

\section{Acknowledgements}

X.S. and P.W. contributed equally to this work. This work was supported by funding from the National Basic Research Program of China (973-program) under the Grant No. 2013CB632500 and the Natural Science Foundation of China (Grant No. 51521001). C.U. and X.T. also acknowledge support provided by CERC-CVC under the Award Number DE-PI0000012.

Received: April 15, 2016 Published online: January 23, 2017

[1] N. S. Lewis, D. G. Nocera, Proc. Natl. Acad. Sci. U.S.A. 2006, 103, 15729.

[2] T. M. Tritt, M. A. Subramanian, MRS Bulletin 2006, 31, 188.

[3] P. V. Kamat, J. Phys. Chem. C 2007, 111, 2834.

[4] H. Lund, Energy 2007, 32, 912.

[5] M. S. Dresselhaus, G. Chen, M. Y. Tang, R. G. Yang, H. Lee, D. Z. Wang, Z. F. Ren, J. P. Fleurial, P. Gogna, Adv. Mater. 2007, 19, 1043.

[6] J. R. Sootsman, D. Y. Chung, M. G. Kanatzidis, Angew. Chem. Int. Ed. 2009, 48, 8616

[7] G. Slack, in CRC Handbook of Thermoelectrics (Ed: D. M. Rowe), CRC Press, Boca Raton, FL 1995.

[8] G. S. Nolas, D. T. Morelli, T. M. Tritt, Annu. Rev. Mater. Sci. 1999, 29, 89.

[9] L. E. Bell, Science 2008, 321, 1457.

[10] F. J. DiSalvo, Science 1999, 285, 703.

[11] D. M. Rowe, C. M. Bhandari, Modern Thermoelectrics, Holt, Rinehart and Winston, London, UK, 1983.

[12] C. J. Vineis, A. Shakouri, A. Majumdar, M. G. Kanatzidis, Adv. Mater. 2010, 22, 3970

[13] Y. C. Lan, A. J. Minnich, G. Chen, Z. F. Ren, Adv. Funct. Mater. 2010, 20, 357.

[14] J. Yang, F. R. Stabler, J. Electron. Mater. 2009, 38, 1245.

[15] P. Li, L. L. Cai, P. C. Zhai, X. F. Tang, Q. J. Zhang, M. Niino, J. Electron. Mater. 2010, 39, 1522.
[16] D. Kraemer, B. Poudel, H.-P. Feng, J. C. Caylor, B. Yu, X. Yan, Y. Ma, X. W. Wang, D. Z. Wang, A. Muto, K. McEnaney, M. Chiesa, Z. F. Ren, G. Chen, Nat. Mater. 2011, 10, 532.

[17] Q. H. Zhang, X. Y. Huang, S. Q. Bai, X. Shi, C. Uher, L. D. Chen, Adv. Engin. Mater. 2016, 18, 194.

[18] G. J. Snyder, E. S. Toberer, Nat. Mater. 2008, 7, 105.

[19] C. Xiao, Z. Li, K. Li, P. C. Huang, Y. Xie, Acc. Chem. Res. 2014, 47, 1287.

[20] T. C. Harman, P. J. Taylor, M. P. Walsh, B. E. LaForge, Science 2002, 297, 2229.

[21] J. R. Lim, J.F. Whitacre, J.-P. Fleurial, C.-K. Huang, M.A. Ryan, N.V. Myung, Adv. Mater. 2005, 17, 1488.

[22] W. Wang, F. L. Jia, Q. H. Huang, J. Z. Zhang, Microelectron. Eng. 2005, 77, 223.

[23] Y. Li, K. Buddharaju, N. Singh, G. Q. Lo, S. J. Lee, IEEE Electr. Device L. 2011, 32, 674.

[24] I. Chowdhury, R. Prasher, K. Lofgreen, G. Chrysler, S. Narasimhan, R. Mahajan, D. Koester, R. Alley, R. Venkatasubramanian, Nat. Nanotechnol. 2009, 4, 235.

[25] Y. Z. Pei, H. Wang, G. J. Snyder, Adv. Mater. 2012, 24, 6125.

[26] G. D. Mahan, J. O. Sofo, Proc. Natl. Acad. Sci. U.S.A. 1996, 93, 7436.

[27] J. L. Cohn, G. S. Nolas, V. Fessatidis, T. H. Metcalf, G. A. Slack, Phys. Rev. Lett. 1999, 82, 779.

[28] B. C. Sales, D. Mandrus, B. C. Chakoumakos, V. Keppens, J. R. Thompson, Phys. Rev. B 1997, 56, 15081.

[29] V. Keppens, D. Mandrus, B. C. Sales, B. C. Chakoumakos, P. Dai, R. Coldea, M. B. Maple, D. A. Gajewski, E. J. Freeman, S. Bennington, Nature 1998, 395, 876.

[30] M. M. Koza, M. R. Johnson, R. Viennois, H. Mutka, L. Girard, D. Ravot, Nat. Mater. 2008, 7, 805.

[31] Y. Wang, X. Xu, J. Yang, Phys. Rev. Lett. 2009, 102, 175508.

[32] H. Liu, X. Shi, F. Xu, L. Zhang, W. Zhang, L. Chen, Q. Li, C. Uher, T. Day, G. J. Snyder, Nat. Mater. 2012, 11, 422.

[33] S. Lee, K. Esfarjani, T. Luo, J. Zhou, Z. Tian, G. Chen, Nat. Comm. 2014, 5, 3525.

[34] S. Wang, J. Yang, L. Wu, P. Wei, Jihui Yang, W. Zhang, Y. Grin, Chem. Mater. 2015, 27, 1071.

[35] M. D. Nielsen, V. Ozolins, J. P. Heremans, Energy Environ. Sci. 2013, 6, 570 .

[36] E. J. Skoug, D. T. Morelli, Phys. Rev. Lett. 2011, 107, 235901.

[37] W. Qiu, L. Xi, P. Wei, X. Ke, J. Yang, W. Zhang, Proc. Natl. Acad. Sci. U.S.A. 2014, 111, 15031.

[38] L. D. Zhao, S. H. Lo, Y. Zhang, H. Sun, G. Tan, C. Uher, C. Wolverton, V. P. Dravid, M. G. Kanatzidis, Nature 2014, 508, 373

[39] M. Cutler, N. F. Mott, Phys. Rev. 1969, 181, 1336.

[40] P. J. Sun, B. P. Wei, J. H. Zhang, J. M. Tomczak, A. M. Strydom, M. Søndergaard, B. B. Iversen, F. Steglich, Nat. Commun. 2015, 6, 7475.

[41] J. S. Dyck, W. D. Chen, C. Uher, L. Chen, X. F. Tang, T. Hirai, J. Appl. Phys. 2002, 91, 3698

[42] S. Y. Wang, J. Yang, L. H. Wu, P. Wei, W. Q. Zhang, J. H. Yang, Adv. Funct. Mater. 2015, 25, 6660.

[43] T. E. Humphrey, H. Linke, Phys. Rev. Lett. 2005, 94, 096601.

[44] J. M. O. Zide, D. Vashaee, Z. X. Bian, G. Zeng, J. E. Bowers, A. Shakouri, A. C. Gossard, Phys. Rev. B 2006, 74, 205335.

[45] J. P. Heremans, C. M. Thrush, D. T. Morelli, Phys. Rev. B 2004, 70, 115334.

[46] J. P. Heremans, C. M. Jaworski, Appl. Phys. Lett. 2008, 93, 122107.

[47] N. Gothard, X. Ji, J. He, T. M. Tritt, J. Appl. Phys. 2008, 103, 054314.

[48] H. L. Liu, X. Yuan, P. Lu, X. Shi, F. F. Xu, Y. He, Y. S. Tang, S. Q. Bai, W. Q. Zhang, L. D. Chen, Y. Lin, L. Shi, H. Lin, X. Y. Gao, X. M. Zhang, H. Chi, C. Uher, Adv. Mater. 2013, 25, 6607. 
[49] Y. Xu, Z. X. Gan, S.-C. Zhang, Phys. Rev. Lett. 2014, 112, 226801.

[50] Y. Z. Pei, X. Y. Shi, A. LaLonde, H. Wang, L. D. Chen, G. J. Snyder, Nature 2011, 473, 66

[51] S. Ahmad, K. Hoang, S. D. Mahanti, Phys. Rev. Lett. 2006, 96 , 056403.

[52] J. P. Heremans, B. Wiendlocha, A. M. Chamoire, Energy Environ. Sci. 2012, 5, 5510

[53] L. D. Zhao, V. P. Dravid, M. G. Kanatzidis, Energy Environ. Sci. 2014, 7, 251

[54] C. M. Jaworski, M. D. Nielsen, H. Wang, S. N. Girard, W. Cai, W. D. Porter, M. G. Kanatzidis, J. P. Heremans, Phys. Rev. B 2013 , 87, 045203.

[55] W. Liu, X. J. Tan, K. Yin, H. J. Liu, X. F. Tang, J. Shi, Q. J. Zhang, C. Uher, Phys. Rev. Lett. 2012, 108, 166601.

[56] L. D. Zhao, S. Hao, S. H. Lo, C. I. Wu, X. Zhou, Y. Lee, H. Li, K. Biswas, T. P. Hogan, C. Uher, C. Wolverton, V. P. Dravid, M. G. Kanatzidis, J. Am. Chem. Soc. 2013, 135, 7364.

[57] Y. Chen, C. M. Jaworski, Y. B. Gao, H. Wang, T. J. Zhu, G. J. Snyder, J. P. Heremans, X. B. Zhao, New J. Phys. 2014, 16, 013057.

[58] H. Wang, Z. M. Gibbs, Y. Takagiwa, G. J. Snyder, Energy Environ. Sci. 2014, 7, 804.

[59] G. Tan, L.-D. Zhao, F. Shi, J. W. Doak, S.-H. Lo, H. Sun, C. Wolverton, V. P. Dravid, C. Uher, M. G. Kanatzidis, J. Am. Chem. Soc. 2014, 136, 7006.

[60] Y. L. Tang, Z. M. Gibbs, L. A. Agapito, G. D. Li, H.-S. Kim, M. B. Nardelli, S. Curtarolo, G. J. Snyder, Nat. Mater. 2015, 14, 1223.

[61] M. O ko, S. Žonja, I. Aviani, E. D. Bauerc, J. L. Sarrao, J. Alloy. Compd. 2011, 509, 6999.

[62] J. P. Heremans, V. Jovovic, E. S. Toberer, A. Saramat, K. Kurosaki, A. Charoenphakdee, S. Yamanaka, G. J. Snyder, Science 2008, 321 554.

[63] Q. Zhang, B. Liao, Y. Lan, K. Lukas, W. Liu, K. Esfarjani, C. Opeil, D. Broido, G. Chen, Z. Ren, Proc. Natl. Acad. Sci. U.S.A. 2013, 110, 13261.

[64] Q. Zhang, H. Wang, W. Liu, H. Wang, B. Yu, Q. Zhang, Z. Tian, G. Ni, S. Lee, K. Esfarjani, G. Chen, Z. Ren, Energy Environ. Sci. 2012, 5, 5246 .

[65] C. M. Jaworski, V. A. Kulbachinskii, J. P. Heremans, Phys. Rev. B 2009, 80, 233201

[66] T. Zou, W. Xie, J. Feng, X. Qin, A. Weidenkaff, J. Nanomater. 2015, 2015, 642909.

[67] W. Y. Zhao, P. Wei, Q. J. Zhang, H. Peng, W. T. Zhu, D. G. Tang, J. Yu, H. Y. Zhou, Z. Y. Liu, X. Mu, D. Q. He, J. C. Li, C. L. Wang, X. F. Tang, J. H. Yang, Nat. Comm. 2015, 6, 6197.

[68] T. He, J. Chen, H. D. Rosenfeld, M. A. Subramanian, Chem. Mater. 2006, 18, 759 .

[69] W. Y. Zhao, P. Wei, Q. J. Zhang, C. L. Dong, L. S. Liu, X. F. Tang, J. Am. Chem. Soc. 2009, 131, 3713.

[70] W. Y. Zhao, C. L. Dong, P. Wei, W. Guan, L. S. Liu, P. C. Zhai, X. F. Tang, Q. J. Zhang, J. Appl. Phys. 2007, 102, 113708

[71] J. Eilertsen, S. Rouvimov, M. A. Subramanian, Acta Mater. 2012 60, 2178.

[72] Y. L. Tang, Y. T. Qiu, L. L. Xi, X. Shi, W. Q. Zhang, L. D. Chen, S.-M. Tseng, S.-W. Chen, G. J. Snyder, Energy Environ. Sci. 2014, 7, 812.

[73] J. Zhou, R. G. Yang, G. Chen, M. S. Dresselhaus, Phys. Rev. Lett. 2011, 107, 226601

[74] J. Yang, L. Xi, W. Qiu, L. Wu, X. Shi, L. Chen, J. Yang, W. Zhang, C. Uher, D. J. Singh, NPJ Comput. Mater. 2016, 2, 15015.

[75] L. D. Hicks, M. S. Dresselhaus, Phys. Rev. B 1993, 47, 16631.

[76] L. D. Hicks, M. S. Dresselhaus, Phys. Rev. B 1993, 47, 12727.

[77] L. Yu-Ming, O. Rabin, S. B. Cronin, J. Y. Ying, M. S. Dresselhaus, Appl. Phys. Lett. 2002, 81, 2403.
[78] D. G. Cahill, W. K. Ford, K. E. Goodson, G. D. Mahan, A. Majumdar, H. J. Maris, R. Merlin, S. R. Phillpot, J. Appl. Phys. 2003, 93, 793.

[79] D. G. Cahill, P. V. Braun, G. Chen, D. R. Clarke, S. Fan, K. E. Goodson, P. Keblinski, W. P. King, G. D. Mahan, A. Majumdar, H. J. Maris, S. R. Phillpot, E. Pop, L. Shi, Appl. Phys. Rev. 2014, 1, 011305.

[80] P. Pichanusakorn, P. Bandaru, Mater. Sci. Engin. R 2010, 67, 19.

[81] R. Venkatasubramanian, E. Siivola, T. Colpitts, B. O'Quinn, Nature 2001, 413, 597.

[82] T. C. Harman, M. P. Walsh, B. E. LaForge, G. W. Turner, J. Electron. Mater. 2005, 34, L19.

[83] K. F. Hsu, S. Loo, F. Guo, W. Chen, J. S. Dyck, C. Uher, T. Hogan, E. K. Polychroniadis, M. G. Kanatzidis, Science 2004, 303, 818.

[84] C. Dames, G. Chen, Thermoelectrics Handbook: Macro to Nano, CRC Press, Boca Raton, FL 2005

[85] B. Poudel, Q. Hao, Y. Ma, Y. Lan, A. Minnich, B. Yu, X. Yan, D. Wang, A. Muto, D. Vashaee, X. Chen, J. Liu, M. S. Dresselhaus, G. Chen, Z. Ren, Science 2008, 320, 634.

[86] J. F. Li, W. S. Liu, L. D. Zhao, M. Zhou, NPG Asia Mater. 2010, 2, 152.

[87] W. J. Xie, A. Weidenkaff, X. F. Tang, Q. J. Zhang, J. Poon, T. M. Tritt, Nanomaterials 2012, 2, 379

[88] J. Yang, H.-L. Yip, A. K.-Y. Jen, Adv. Energy Mater. 2013, 3, 549.

[89] P. C. Zhai, W. Y. Zhao, Y. Li, L. S. Liu, X. F. Tang, Q. J. Zhang, Appl. Phys. Lett. 2006, 89, 052111.

[90] K. Biswas, J. Q. He, Q. C. Zhang, G. Y. Wang, C. Uher, V. P. Dravid M. G. Kanatzidis, Nat. Chem. 2011, 3, 160.

[91] L. D. Zhao, J. Q. He, S. Q. Hao, C. I. Wu, T. P. Hogan, C. Wolverton, V. P. Dravid, M. G. Kanatzidis, J. Am. Chem. Soc 2012, 134, 16327.

[92] M. Zhou, J. F. Li, T. Kita, J. Am. Chem. Soc. 2008, 130, 4527.

[93] W. Y. Zhao, Z. Liang, P. Wei, J. Yu, Q. J. Zhang, G. S. Shao, Acto Mater. 2012, 60, 1741

[94] X. P. Huang, X. W. Wang, J. Phys. Chem. C 2010, 114, 21003.

[95] W. J. Xie, J. He, H. J. Kang, X. F. Tang, S. Zhu, M. Laver, S. Y. Wang, J. R. D. Copley, C. M. Brown, Q. J. Zhang, T. M. Tritt, Nano Lett. 2010, 10, 3283.

[96] Y. He, P. Lu, X. Shi, F. Xu, T. Zhang, G. J. Snyder, C. Uher, L. Chen, Adv. Mater. 2015, 27, 3639

[97] H. J. Wu, F. S. Zheng, D. Wua, Z. H. Ge, X. Y. Liu, J. Q. He, Nano Energy 2015, 13, 626.

[98] K. Biswas, J. He, I. D. Blum, C. I. Wu, T. P. Hogan, D. N. Seidman, V. P. Dravid, M. G. Kanatzidis, Nature 2012, 489, 414.

[99] J. L. Mi, X. B. Zhao, T. J. Zhu, J. P. Tu, Appl. Phys. Lett. 2007, 91, 172116.

[100] L. D. Zhao, B. P. Zhang, W. S. Liu, J. F. Li, J. Appl. Phys. 2009, 105, 023704 .

[101] J. Yu, W. Y. Zhao, P. Wei, W. T. Zhu, H. Y. Zhou, Z. Y. Liu, D. G. Tang, B. Lei, Q. J. Zhang, Appl. Phys. Lett. 2014, 104, 142104.

[102] Y. Zheng, Q. Zhang, X. L. Su, H. Y. Xie, S. C. Shu, T. L. Chen, G. J. Tan, Y. G. Yan, X. F. Tang, C. Uher, G. J. Snyder, Adv. Energy Mater. 2014, 5, 1401391.

[103] L. P. Hu, H. J. Wu, T. J. Zhu, C. G. Fu, J. Q. He, P. J. Ying, X. B. Zhao, Adv. Energy Mater. 2015, 5, 1500411.

[104] X. L. Su, H. Li, X. F. Tang, J. Phys. D: App. Phys. 2010, 43, 015403.

[105] W. Q. Cao, Y. G. Yan, X. F. Tang, S. K. Deng, J. Phys. D: App. Phys. 2008, 41, 215105

[106] X. F. Tang, P. Li, S. K. Deng, Q. J. Zhang, J. Appl. Phys. 2008, 104, 013706.

[107] S. K. Deng, X. F. Tang, P. Li, Q. J. Zhang, J. Appl. Phys. 2008, 103, 073503.

[108] X. L. Su, X. F. Tang, H. Li, S. K. Deng, Acta Phys. Sin. 2008, $10,069$. 
[109] X. Shi, H. Kong, C.-P. Li, C. Uher, J. Yang, J. R. Salvador, H. Wang, L. Chen, W. Zhang, Appl. Phys. Lett. 2008, 92, 182101.

[110] G. S. Nolas, G. A. Slack, D. T. Morelli, T. M. Tritt, A. C. Ehrlich, J. Appl. Phys. 1996, 79, 4002.

[111] T. M. Tritt, G. S. Nolas, G. A. Slack, A. C. Ehrlich, D. J. Gillespie, J. L. Cohn, J. Appl. Phys. 1996, 79, 8412.

[112] X. Shi, Jiong Yang, J. R. Salvador, M. Chi, J. Y. Cho, H. Wang, S. Bai, J. Yang, W. Zhang, L. D. Chen, J. Am. Chem. Soc. 2011, 133, 7837.

[113] X. L. Su, H. Li, Y. G. Yan, H. Chi, X. F. Tang, Q. J. Zhang, C. Uher, J. Mater. Chem. 2012, 22, 15628.

[114] W. Liu, H. Chi, H. Sun, Q. Zhang, K. Yin, X. F. Tang, Q. J. Zhang, C. Uher, Phys. Chem. Chem. Phys. 2014, 16, 6893.

[115] W. Liu, X. F. Tang, H. Li, K. Yin, J. Sharp, X. Y. Zhou, C. Uher, J. Mater. Chem. 2012, 22, 13653.

[116] J. J. Shen, T. J. Zhu, X. B. Zhao, S. N. Zhang, S. H. Yang, Z. Z. Yin, Energy Environ. Sci. 2010, 3, 1519.

[117] Q. Zhang, Y. Zheng, X. L. Su, K. Yin, X. F. Tang, C. Uher, Scripta Mater. 2015, 96, 1.

[118] W. J. Xie, X. F. Tang, Y. G. Yan, Q. J. Zhang, T. M. Tritt, Appl. Phys. Lett. 2009, 94, 102111.

[119] W. J. Xie, X. F. Tang, Y. G. Yan, Q. J. Zhang, T. M. Tritt, J. Appl. Phys. 2009, 105, 113713.

[120] W. J. Xie, D. A. Hitchcock, H. J. Kang, J. He, X. F. Tang, M. Laver, B. Hammouda, Appl. Phys. Lett. 2012, 101, 113902.

[121] W. J. Xie, S. Y. Wang, S. Zhu, J. He, X. F. Tang, Q. J. Zhang, T. M. Tritt, J. Mater. Sci. 2013, 48, 2745.

[122] G. J. Tan, Y. Zheng, X. F. Tang, Appl. Phys. Lett. 2013, 103, 183904

[123] G. J. Tan, W. Liu, S. Y. Wang, Y. G. Yan, H. Li, X. F. Tang, C. Uher, J. Mater. Chem. A 2013, 1, 12657.

[124] J. Zhou, Q. Jie, L. Wu, I. Dimitrov, Q. Li, X. Shi, J. Mater. Res. 2011, 26, 1842.

[125] X. L. Su, H. Li, Y. G. Yan, G. Y. Wang, H. Chi, X. Y. Zhou, X. F. Tang, Q. J. Zhang, C. Uher, Acta Mater. 2012, 60, 3536.

[126] L. Guo, G. Wang, K. Peng, Y. Yan, X. Tang, M. Zeng, J. Dai, G. Wang, X. Zhou, Scripta Mater. 2016, 116, 26.

[127] H. Li, X. F. Tang, Q. J. Zhang, J. Electron. Mater. 2009, 38, 1224.

[128] H. Li, X. Tang, X. L. Su, Q. J. Zhang, C. Uher, J. Phys. D: Appl. Phys. 2009, 42, 145409

[129] H. Li, X. F. Tang, Q. J. Zhang, C. Uher, Appl. Phys. Lett. 2008, 93, 252109.

[130] H. Li, X. F. Tang, X. L. Su, Q. J. Zhang, Appl. Phys. Lett. 2008, 92, 202114.

[131] Y. G. Yan, W. Wong-Ng, J. A. Kaduk, G. J. Tan, W. J. Xie, X. F. Tang, Appl. Phys. Lett. 2011, 98, 142106.

[132] Y. G. Yan, X. F. Tang, P. Li, Q. J. Zhang, J. Electron. Mater. 2009, $38,1278$.

[133] X. L. Su, X. F. Tang, H. Li, Acta Phys. Sin. 2010, 4, 2860.

[134] T. T. Luo, S. Y. Wang, H. Li, X. F. Tang, Intermetallics 2013, 32, 96.
[135] W. H. Luo, H. Li, Y. G. Yan, Z. B. Lin, X. F. Tang, Q. J. Zhang, C. Uher, Intermetallics 2011, 19, 404.

[136] B. L. Du, H. Li, J. J. Xu, X. F. Tang, C. Uher, J. Solid State Chem. 2011, 184, 109.

[137] D. Qi, X. Tang, H. Li, Y. Yan, Q. Zhang, J. Electron. Mater. 2010, 39, 1159.

[138] S. Wang, H. Li, D. Qi, W. Xie, X. Tang, Acta Mater. 2011, 59, 4805.

[139] S. Wang, W. Xie, H. Li, X. Tang, J. Phys. D: Appl. Phys. 2010, 43, 335404.

[140] S. Wang, W. Xie, H. Li, X. Tang, Acta Phys. Sin. 2010, 59, 8927.

[141] W. Q. Cao, S. K. Deng, X. F. Tang, P. Li, Acta Phys. Sin. 2009, 58, 612.

[142] S. I. Kim, K. H. Lee, H. A. Mun, H. S. Kim, S. W. Hwang, J. W. Roh, D. J. Yang, W. H. Shin, X. S. Li, Y. H. Lee, G. J. Snyder, S. W. Kim, Science 2015, 348, 109.

[143] X. Su, F. Fu, Y. Yan, G. Zheng, T. Liang, Q. Zhang, X. Cheng, D. Yang, H. Chi, X. Tang, Q. Zhang, C. Uher, Nat. Comm. 2014, 5, 4908.

[144] G. Zheng, X. Su, T. Liang, Q. Lu, Y. Yan, C. Uher, X. Tang, J. Mater. Chem. A 2015, 3, 6603.

[145] T. Liang, X. L. Su, Y. G. Yan, G. Zheng, Q. J. Zhang, H. Chi, X. F. Tang, C. Uher, J. Mater. Chem. A 2014, 2, 17914.

[146] T. Liang, X. L. Su, X. M. Tan, G. Zheng, X. Y. She, Y. G. Yan, X. F. Tang, C. Uher, J. Mater. Chem. C 2015, 3, 8550.

[147] X. Y. She, X. L. Su, H. Z. Du, T. Liang, G. Zheng, Y. G. Yan, R. Akram, C. Uher, X. F. Tang, J. Mater. Chem. C 2015, 3, 12116.

[148] Q. Zhang, X. L. Su, Y. G. Yan, H. Xie, T. Liang, Y. G. You, X. F. Tang, C. Uher, ACS Appl. Mater. Inter. 2016, 8, 3268.

[149] H. C. Yi, J. J. Moore, J. Mater. Sci. 1990, 25, 1159.

[150] A. Hendaoui, M. Andasmas, A. Amara, A. Benaldjia, P. Langlois, D. Vrel, Int. J. Self-Propag. High-Temp Synth. 2008, 17, 129.

[151] B. Y. Li, L. J. Rong, Y. Y. Li, V. E Gjunter, Acta Mater. 2000, 48, 3895.

[152] A. G. Merzhanov, in Combustion Processes in Chemical Technology and Metallurgy [in Russian], (Ed: A. G. Merzhanov, Chernogolovska), Russia, 1975.

[153] Z. A. Munir, U. Anselmi-Tamburini, Mater. Sci. Rep. 1989, 3, 277.

[154] J. J. Moore, H. J. Feng, Prog. Mater. Sci. 1995, 39, 243.

[155] Q. J. Zhang, X. F. Tang, P. C. Zhai, M. Niino, C. Endo, Mater. Sci. Forum 2005, 492-493, 135

[156] J. S. Xiao, T. Q. Yang, P. Li, P. C. Zhai, Q. J. Zhang, Appl. Energy 2012, 93, 33.

[157] Y. D. Deng, S. Chen, X. Liu, Mater. Sci. Forum 2013, 743-744, 88.

[158] Y. P. Wang, C. Wu, Z. B. Tang, X. Yang, Y. D. Deng, C. Q. Su, J. Electron. Mater. 2015, 44, 1724.

[159] Y. D. Deng, Y. Zhang, C. Q. Su, J. Electron. Mater. 2015, 44, 1491.

[160] Y. P. Wang, S. Li, X. Yang, Y. D. Deng, C. Q. Su, J. Electron. Mater. 2016, 45, 1792 